\title{
The Quality of Work Environment of Nurses in A Public Hospital in Negros Occidental
}

\author{
Susan Jane T. Adis ${ }^{1}$ and Sheila P. Arnibal ${ }^{2}$ \\ ${ }^{1}$ Lorenzo Decena Zayco District Hospital, Kabankalan City, Negros Occidental, Philippines \\ 2University of Negros Occidental-Recoletos, Bacolod City, Philippines
}

\begin{tabular}{l} 
Article history \\
Submitted: 23 October 2020 \\
Revised: 4 November 2020 \\
Accepted: 13 November 2020 \\
\hline Keywords \\
Nursing \\
Work Environment \\
Nurses \\
Public Hospital \\
Descriptive-Comparative \\
Negros Occidental
\end{tabular}

Introduction. The World Health Organization Regional Office of the Western Pacific's definition of a healthy workplace is a place where all members work together to achieve a unified vision for the health and well-being of the workers and the community. A healthy work environment is where all members are provided with the physical, psychological, social, and organizational states that protect and promote their health and safety. A positive work environment for nurses has been concisely described as a work environment where nurses are supported to function at the highest scope of clinical practice, working effectively in an interdisciplinary manner with the team of caregivers mobilizing resources quickly. This paper describes the level of quality of the work environment of nurses in a public hospital in Negros Occidental. Likewise, it explores the difference in the level of quality of the work environment when nurses are grouped according to their demographics. Also, it determines the challenges encountered by nurses in their work environment.

Methods. A descriptive-comparative research design was used to assess and compare the level of quality of the work environment of nurses in a public hospital in Negros Occidental. Using stratified random sampling, 62 nurses participated in the study. The respondents were the regular and contractual staff nurses, supervisors, and the chief nurse. The data were gathered using a researchermade instrument that undergone reliability and validity testing before utilization. To determine the quality of the work environment of nurses at the Public Hospital in Negros Occidental, the descriptive analysis was used, with the mean as a statistical tool. For problems seeking a significant difference in the quality of work environment, a comparative analysis was used utilizing the t-test. The work environment's challenges were subjected to descriptive analysis using the frequency count, percentage distribution, Mean, and Standard Deviation.

Results. The findings of the study revealed that the nurses in a public hospital in Negros Occidental feel positive about their work environment most of the time when they are grouped according to age, sex, years of service, employment status, educational attainment, and area of assignment. The work environment of these nurses can be considered healthy because the nurses rated the quality of their work environment as very good. As to the significant difference, results showed no significant difference in the level of quality of work environment of nurses in the area of physical, psychosocial, personal health resources, and enterprise community involvement when nurses are grouped according to their demographics. However, a significant difference was shown in the level of quality of the work environment of nurses in the area of physical and personal health resources when they are grouped according to their employment status. Lastly, the challenges encountered by nurses in their work environment showed the nurse-patient ratio and few equipment/materials were the highest according to their frequency and percentage.

Conclusion. The results of the study show that nurses in a public hospital in Negros Occidental feel positive about their work environment most of the time. This implies that nurses can perform well with their duties and responsibilities, given the work environment they are in. Variables such as sex, age, years of service, employment status, educational attainment, and area of assignment do not influence their view on the level of quality of their work environment. Certain challenges encountered by nurses were mentioned, such as the nurse-patient ratio of more than 1:12, few equipment/ 
materials, working more than 8 hours, and lesser opportunities for training. These challenges influence the quality of nurses' performance in their work from which their working environment is being affected.

Practical Value of the Paper. This study will primarily benefit the hospital administrators of a public hospital in Negros Occidental. Also, the findings of this study will help the institution identify the effects of the working environment on the attitude exhibited by the nurses and design a program to assist them in dealing with workplace stress and to cope effectively without compromising the services given to the patients.

\section{References}

Fathi, A. (2010). Workplace stressors and coping strategies among public hospital nurses in Medan, Indonesia (Doctoral dissertation, Prince of Songkla University).

Babanataj, R., Mazdarani, S., Hesamzadeh, A., Gorji, M. H., \& Cherati, J. Y. (2019). Resilience training: Effects on occupational stress and resilience of critical care nurses. International journal of nursing practice, 25(1), e12697.

Dayma, D. L., \& Mohan, M. (2017). Psychological well-being of nursing staff employed in government and private hospitals. International Journal of Education and Management Studies, 7(1), 27.

Van Doorn, Y., Van Ruysseveldt, J., Van Dam, K., Mistiaen, W., \& Nikolova, I. (2016). Understanding the well-being and learning of Nigerian nurses: a job demand control support model approach. Journal of nursing management, 24(7), 915-922.

Ghavidel, F., Fallahi-Khoshknab, M., Molavynejad, S., \& Zarea, K. (2019). The role of organizational factors in nurse burnout: Experiences from Iranian nurses working in psychiatric wards. Journal of Family Medicine and Primary Care, 8(12), 3893.

Jahan, T., \& Kiran, U. V. (2013). An evaluation of the Job Satisfaction of Nurses across the working sector. International Journal of Humanities and Social Science Invention, 2(6), 37-39.

Rivaz, M., Momennasab, M., Yektatalab, S., \& Ebadi, A. (2017). Adequate resources as an essential component in the nursing practice environment: a qualitative study. Journal of clinical and diagnostic research: JCDR, 11(6), IC01.

Watanabe, M., \& Yamauchi, K. (2018). The effect of quality of overtime work on nurses' mental health and work engagement. Journal of Nursing Management, 26(6), 679-688.

Younas, A., \& Sundus, A. (2018). Experiences of and satisfaction with care provided by male nurses: A convergent mixed-method study of patients in medical-surgical units. Journal of advanced nursing, 74(11), 2640-2653.

\section{Correspondence:}

Susan Jane T. Adis [keemsan101817@gmail.com]

https://orcid.org/0000-0002-4283-7429 